\title{
Odontogeriatría y gerodontología: envejecimiento y las características bucales del paciente adulto mayor: Revisión de literatura
}

\author{
Geriatric dentistry and gerodontology: aging and oral characteristics of elderly patients. Review
}

Beatriz Del Carmen Chávez-Reátegui ${ }^{1, a, c}$, Jorge Enrique Manrique-Chávez ${ }^{2, d}$, Jorge Adalberto ManriqueGuzmán

\section{RESUMEN}

Las tendencias demográficas a nivel mundial han demostrado un aumento de la población de adultos mayores, y en el Perú esa situación no es la excepción. Este fenómeno demográfico plantea muchos retos en el campo de la salud, uno de los cuales es la formación de profesionales especializados y comprometidos para atender a este grupo etario. En el campo odontológico, el adulto mayor puede presentar múltiples enfermedades bucales como caries dental, enfermedad periodontal, lesiones en la mucosa oral, candidiasis e inclusive cáncer oral, siendo las más destacadas la caries dental y la enfermedad periodontal. Otras manifestaciones clínicas que se producen en boca y que son muy frecuentes son la pérdida de hueso alveolar, movilidad dental y disminución del gusto que provocan disminución del apetito y, por consiguiente, la baja de peso e inclusive anemia. Por otro lado, es común que la población geriátrica presente una serie de complicaciones que han de ser abordadas conjuntamente por el odontólogo y el médico tratante. Este grupo poblacional padece enfermedades crónicas como consecuencia del proceso natural de envejecimiento en el cual ocurren cambios o modificaciones a nivel molecular, celular, tisular y orgánico que contribuyen a la progresiva disminución de la capacidad del organismo

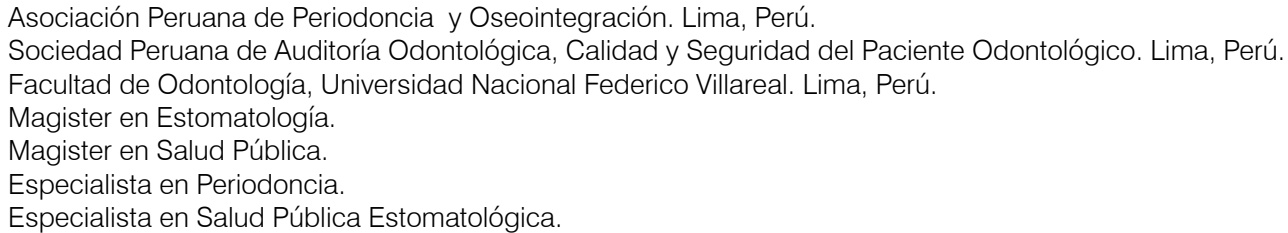


para mantener su viabilidad. La presente revisión bibliográfica aporta las bases conceptuales del envejecimiento y las características bucales del paciente adulto mayor, lo cual va a permitir un mayor conocimiento del campo de acción de la odontogeriatría y gerodontología.

PALABRAS CLAVE: Odontología geriátrica, geriatría, gerontología, anciano, envejecimiento, salud del anciano, servicios de salud para ancianos. (DeCS, BIREME)

\section{SUMMARY}

Demographic trends worldwide have shown an increase in elderly population and the situation in Peru is no exception. This demographic phenomenon poses many challenges in the field of health, one of which is the formation of specialized professionals committed to serving this age group. In the dental field, the elderly may have multiple oral diseases such as dental caries, periodontal disease, oral mucosal lesions, oral candidiasis and even oral cancer, the most prominent dental caries and periodontal disease. Other clinical manifestations that occur in the mouth and are very common are alveolar bone loss, tooth mobility and decreased taste that cause decreased appetite and consequently, low weight and even anemia. Furthermore, it is common for the geriatric population presents a number of complications that have to be addressed jointly by the dentist and the treating physician. This population suffers from chronic illnesses as a result of the natural aging process in which changes or modifications at the molecular, cellular, tissue and organ contributing to the gradual decline in the body's ability to maintain viability occur. This literature review provides the conceptual basis of aging and oral characteristics of elderly patients, which will allow a better understanding of the scope of geriatric dentistry and gerodontology.

KEYWORDS: Geriatric dentistry, geriatrics, gerontology, aged, aging, health of the elderly, health services for the aged. (MeSH, NLM)

\section{INTRODUCCIÓN}

La odontología geriátrica se define como la rama de la odontología que se ocupa de los problemas odontológicos de las personas mayores (1). En un amplio sentido de la palabra, se orienta a la atención de la salud bucal para personas de 65 años de edad y mayores, y para personas de cualquier edad, cuyo estado físico general esté significativamente influenciado por procesos degenerativos $\mathrm{y}$ enfermedades que se asocian habitualmente con la edad avanzada (2).

Es importante conocer, que el adulto mayor suele tener una o más enfermedades crónicas que implican el deterioro físico o mental, con problemas psicosociales asociados y/o derivados de tratamientos medicamentosos, los cuales van a requerir un manejo especial a nivel médico y odontológico $(1,2)$.

Este grupo poblacional padece enfermedades crónicas como consecuencia del proceso natural de envejecimiento, en el cual ocurren cambios o modificaciones a nivel molecular, celular, tisular y orgánico que contribuyen a la progresiva disminución de la capacidad del organismo para mantener su viabilidad. A medida que pasan los años, la gente vive más y conserva cada vez más sus piezas dentarias. Al mismo tiempo, sus demandas son cada vez mayores y requieren de profesionales preparados no solamente en las características odontológicas de los ancianos, sino también en aspectos médicos, gerontológicos y psicológicos, para llegar a un grado de comprensión indispensable que posibilite un buen diagnóstico y un plan de tratamiento adecuado (2-4).

\section{REVISIÓN DE LITERATURA}

El objetivo de la presente revisión de literatura fue realizar una recopilación de la información actual existente sobre las enfermedades bucales más prevalentes en el adulto mayor y la descripción de las manifestaciones clínicas que se producen en la boca como: pérdida de hueso alveolar, movilidad dental y disminución del gusto; que provocan a la vez, disminución del apetito y -como consecuencia 
de esto- una disminución de su peso e inclusive en algunos casos anemia.

\section{Odontogeriatría y gerodontología}

La odontología geriátrica (odontogeriatría), surge en Estados Unidos en los años 60, y fue impulsada por odontólogos interesados en la salud bucodental de la personas mayores bajo un enfoque geriátrico. Así pues, la odontogeriatría, es la especialidad odontológica que tiene como objetivo primordial la prevención, tratamiento y rehabilitación de la salud bucodental de las personas mayores, considerando los cambios biológicos sistémicos y bucales inherentes al envejecimiento (1). Su desarrollo fue más evidente entre los años 1966 a 1979, periodo en el que se publicó la revista internacional Journal of the American Society for Geriatric Dentistry; revista que años más tarde cambiaría su nombre a: "Special Care in Denstistry", debido a la fusión de la Sociedad Americana de Odontología Geriatríca (American Society for Geriatric Dentistry), la Asociación Americana de Dentistas de Hospitales (American Association of Hospital Dentists), la Academia de Odontología para Personas con Discapacidades (Academy of Dentistry for Person with Disabilities) y la Asociación Odontológica de Cuidados Especiales (Special Care Dentistry Association) $(1,2)$.

La gerondontología, derivada de la palabra gerontología, se inicia en Europa a finales de los años 70 y se define como la especialidad odontológica que busca proveer el óptimo cuidado bucodental para adultos mayores, a través de prevención, tratamiento y rehabilitación de las alteraciones bucodentales inherentes al envejecimiento, así como su repercusión odontológica de las enfermedades crónicas degenerativas que se presentan en la vejez (1). Su desarrollo se inició con la Sociedad Británica de Gerodontología (British Society of Gerodontology) dando origen a la revista internacional "Gerodontology" que se publica desde 1982, respaldada por el Colegio Europeo de Gerodontología (European College of Gerodontology) a partir de $1990(1,2)$.

La diferencia entre estas dos especialidades radica en que la gerondotología enfatiza la prevención psicosocial de los problemas bucales de los adultos mayores, un gerodontólogo atiende a personas mayores sanas o enfermas, con el fin de lograr el máximo de salud y bienestar bucodental, considerando los aspectos biológicos, psicológicos y sociales del envejecimiento acorde con el contexto sociocultural. Mientras que los dentistas y clínicas dentales especializadas en odontología geriátrica (odontogeriatría), se encargan de la atención de la salud bucodental de las personas de la tercera edad, considerando los cambios: biológicos, sistémicos y bucales inherentes al envejecimiento; además de abordar los aspectos etiológicos y fisiopatológicos de las alteraciones y complicaciones bucodentales vinculadas con las enfermedades crónicas de mayor prevalencia en la vejez (1-4)

\section{Envejecimiento}

El envejecimiento, es un proceso gradual y adaptativo, caracterizado por una disminución relativa de la respuesta homeostática debido a las modificaciones morfológicas, fisiológicas, bioquímicas y psicológicas, propiciadas por los cambios inherentes a la edad y al desgaste acumulado ante los retos que enfrenta el organismo a lo largo de la historia del individuo en un ambiente determinado

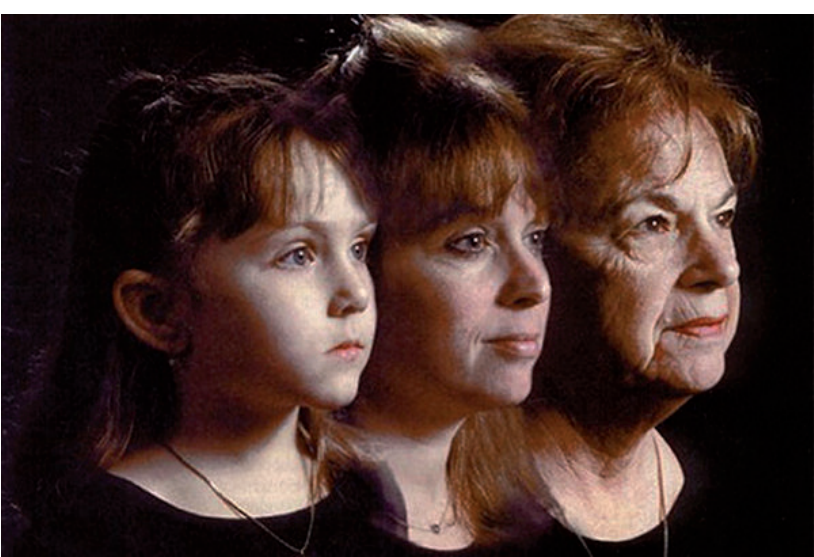

Figura 1. Cambios físicos por envejecimiento (13).

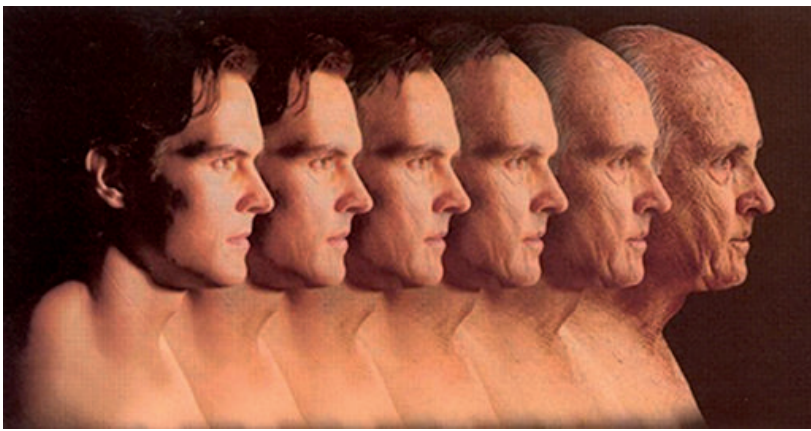

Figura 2. Proceso natural de envejecimiento (14). 
$(5,6)$. Es un proceso deletéreo, progresivo, intrínseco y universal que con el tiempo ocurre en todo ser vivo a consecuencia de la interacción de la genética del individuo y su medio ambiente (7) (Figuras 1 y 2).

Podría definirse también, como todas las alteraciones que se producen en un organismo con el paso del tiempo y que conducen a pérdidas funcionales y a la muerte; o de manera globalizada, podría entenderse al envejecimiento como una sucesión de modificaciones morfológicas, fisiológicas y psicológicas de carácter irreversible, que se presentan antes que las manifestaciones externas den al individuo aspecto de anciano (8).

La Organización Mundial de la Salud (OMS), a finales de los 90, empezó a hablar del envejecimiento activo, refiriéndose al proceso por el que se optimizan las oportunidades de bienestar físico, social y mental durante toda la vida a los individuos como a los grupos de población, con el objetivo de ampliar la esperanza de vida saludable, la productividad y la calidad de vida en la vejez (9). Sus principios permiten delinear los componentes del envejecimiento activo para la actividad social que ha de contribuir al bienestar individual, familiar, comunitario y social $(9,10)$. El envejecimiento a nivel mundial es un hecho real y trascendental que repercute en decisiones políticas y en la demanda social $(11,12)$.

En la actualidad, existen más de 300 teorías que tratan de explicar el proceso de envejecimiento pero, hasta el día de hoy, ninguna de ellas aclara en su totalidad este complicado fenómeno universal, natural, progresivo, individual e irreversible (7).

Una de las clasificaciones más aceptadas en el ámbito gerontológico es la de Hernández y col. (1) que subdivide al adulto mayor en: a) viejos-jóvenes (de 60 a 74 años), b) viejos-viejos (de 75 a 89 años), y c) viejos-longevos (de 90 a más años) (Tabla 1).

\section{Características bucales del paciente geriátrico}

En relación a los tejidos duros, el esmalte del paciente geriátrico sufre un desgaste natural, como resultado de la masticación sin ocasionar molestia. Se observa opacamiento del esmalte, lo que ocasiona que los órganos dentales se vean de color mate, sin brillo y más oscuros. De igual modo, en la dentina hay un cambio de coloración debido al propio proceso de envejecimiento y se produce un cambio muy notorio producido por la sustitución de la dentina original por la denominada "dentina de reparación", lo que ocasiona que los dientes adopten un tono amarillo. Estos cambios generan que las piezas dentarias se vuelven más frágiles por aumento de la mineralización dentinaria (1,15-21) (Figura 3).

Otra de las afecciones presente es la caries cervical, que se localiza en el cuello anatómico de

Tabla 1. Clasificación del envejecimiento (1).

\begin{tabular}{|c|c|c|}
\hline Clasificación & Rango de Edad & Características \\
\hline Viejos-jóvenes & De 60 a 74 años & $\begin{array}{l}\text { Son potencialmente activos y en su mayoría } \\
\text { sanos, desde el punto de gerontológico. } \\
\text { Este grupo de edad representa un capital } \\
\text { social fundamental para el paradigma del } \\
\text { envejecimiento activo. }\end{array}$ \\
\hline Viejos-viejos & De 75 a 89 años & $\begin{array}{l}\text { Tienen mayor riesgo de presentar limitaciones } \\
\text { físicas, psicológicas y sociales. Requieren } \\
\text { de programas gerontológicos diferenciados } \\
\text { para mantener, prolongar y recuperar la } \\
\text { funcionalidad, además de prevenir la fragilidad. }\end{array}$ \\
\hline Viejos-longevos & De 90 y más años & $\begin{array}{l}\text { Grupo poblacional vulnerable desde el punto } \\
\text { de vista biológico, psicológico y social: de ahí } \\
\text { que sea necesario, desarrollar programas de } \\
\text { gerontología asistida para prevenir y controlar } \\
\text { la fragilidad en el ámbito comunitario, en el } \\
\text { marco del envejecimiento activo. }\end{array}$ \\
\hline
\end{tabular}




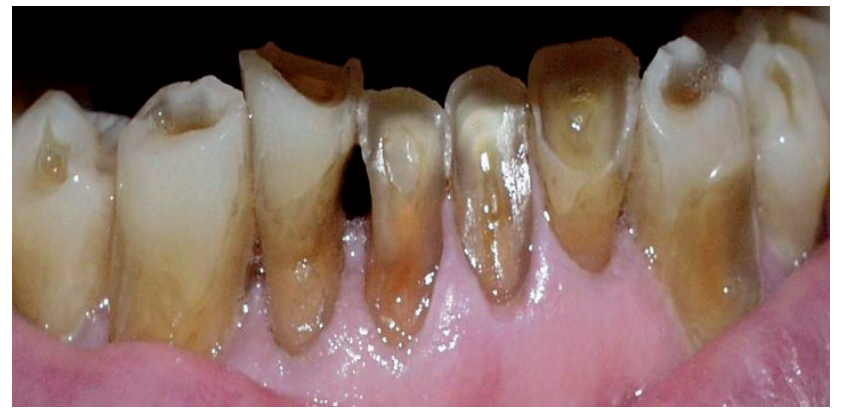

Figura 3. Proceso natural de envejecimiento de las piezas dentarias (17).

los dientes donde el cemento radicular se ha hecho presente por sobre erupción o migración de la encía cuya complicación es la muerte paulatina de los órganos dentarios. A nivel de la pulpa, ésta disminuye su función sensitiva y como consecuencia del envejecimiento se produce pérdida en la elasticidad vascular y fibrosis pulpar asociada al envejecimiento y se promueve su fibrosis $(3,15,16,18)$.

En el aspecto gingival, observamos que la encía de los adultos mayores es de color rosa pálido debido a la disminución en la irrigación sanguínea por la obturación de los capilares submucosos. Además, ésta se encuentra adelgazada y frágil debido a un tejido conectivo deficiente, por lo que tiende a lesionarse con mayor facilidad $(5,6)$, perdiéndose el puntillado característico. A nivel gingival se va produciendo una recesión del tejido dejando descubierta parte de la raíz dental (18). En el tejido periodontal del adulto mayor existe una disminución en la sensibilidad de las fibras periodontales que en ocasiones no permite evidenciar el dolor, esto sumado a la disminución de la destreza manual o psicomotora, propia del envejecimiento, genera la presencia y acumulación de placa bacteriana que conlleva a serios problemas periodontales y caries dental cervical $(5,15,16)$.

Como consecuencia de los problemas en los tejidos duros y periodontales podemos evidenciar serios cuadros de edentulismo. Cuando un adulto mayor presenta edentulismo se ve afectada no sólo la función masticatoria, sino también la fonación, autoestima y estética. Debido a que la pérdida de dientes se suele acentuar durante el envejecimiento; la tendencia común es asociar la degeneración dental con el clásico cuadro de senilidad. Se puede inferir que el estado de salud bucal de la población geriátrica es el reflejo de los cuidados odontológicos

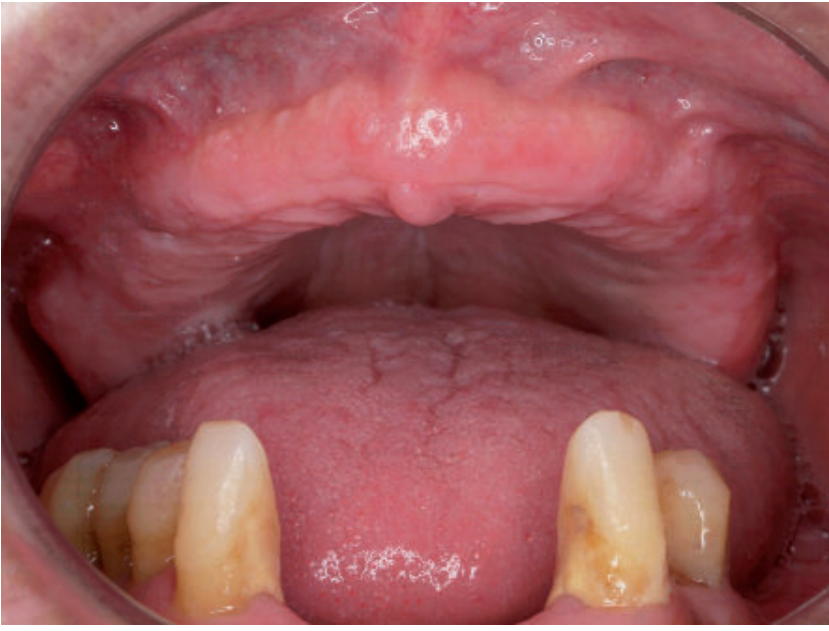

Figura 4. Edentulísmo total y parcial (16).

que durante toda la vida se recibió; sumado a las posibles consideraciones sistémicas que condicionan su estado de salud. En líneas generales, un porcentaje bastante alto de la población de adultos mayores presenta ausencia de por lo menos la mitad de las piezas dentales, y otro porcentaje es desdentado total. Por otro lado, la totalidad de la población geríatica sufre algún grado de enfermedad periodontal que conlleva a la pérdida de soporte, pérdida de inserción, severos cuadros de movilidad dentaria y finalmente, la pérdida de piezas dentarias $(15,16)$ (Figura 4).

En relación a la saliva, ésta disminuye en sus elementos de protección, su estructura se torna más acuosa y de menor calidad; así mismo, su producción disminuye (xerostomía). La cantidad de saliva se ve reflejada proporcionalmente a la ingesta de agua por parte del adulto mayor. Esta disminución del flujo salival afecta negativamente la neutralización de la baja del $\mathrm{pH}$ provocada por el metabolismo bacteriano de la placa, impide el efecto mecánico de arrastre y disminuye considerablemente el aporte de inmunoglobulinas salivares que favorecen la aparición y progresión de caries radiculares (22). Se recomienda el uso de saliva artificial o utilizar menta, hierbabuena o sábila para aumentar la producción salival $(1,3,6)$.

En la lengua hay disminución del número de papilas gustativas (Figura 5), lo que ocasiona que disminuya la percepción de los sabores $(13,19)$. Adicionalmente, por acción del envejecimiento también se observa la presencia de varices sublinguales o varicosidades 


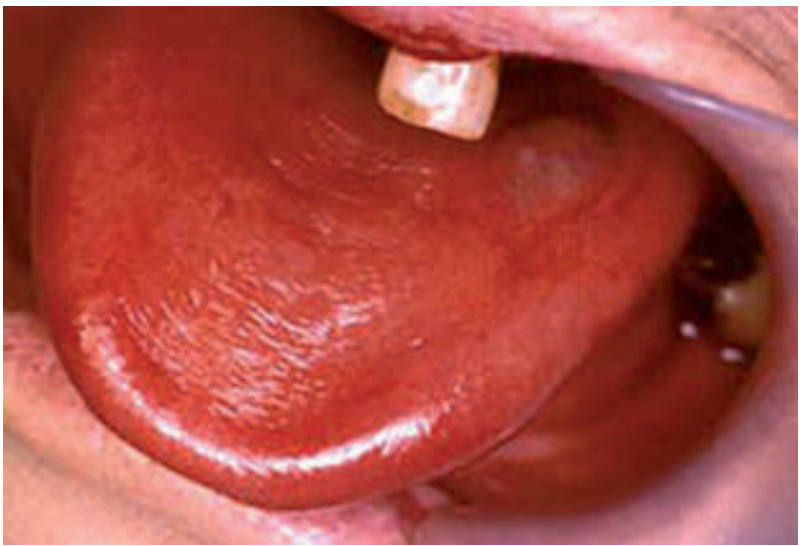

Figura 5. Lengua depapilada y xerostomía (16).

nodulares en la cara ventral de la lengua, o también llamada lengua caviar ya que se observan vasos dilatados y tortuosos que tiene una apariencia redondeada y de color negruzco con similitud al caviar. Estas son dilataciones tortuosas de las venas sublinguales que parecen estar muy condicionadas por la edad ya que son relativamente frecuentes en adultos mayores, en especial mayores de cincuenta años; mientras que son excepcionales en niños o jóvenes. Es normal que existan venas visibles debajo de la lengua, debido a que la membrana mucosa que la cubre es fina y translúcida; influyendo en su desarrollo la pérdida de elasticidad y de tono del tejido conectivo que soportan dichos vasos. No está demostrado que estén asociadas con ninguna enfermedad sistémica, aunque observaciones aisladas las han relacionado con hipertensión arterial, enfermedades cardiopulmonares o varices en miembros inferiores $(1,6,16,22,23)$ (Figura 6).

En la articulación temporomandibular (ATM), producto del envejecimiento, se produce hipertrofia del cartílago por alteraciones degenerativas (1), así como aplanamiento de la superficie articular con reducción del tamaño del cóndilo mandibular que produce mayor laxitud de los movimientos articulares. De igual manera, el disco articular tiende a perforarse con la edad por lo que la actividad propioceptiva disminuye y afecta el control de los movimientos. A nivel radiográfico se observan erosiones y alteraciones de la forma de las superficies articulares y reducción de tamaño del cóndilo mandibular, aumentando la posibilidad de perforación del disco articular, osteoporosis y quistes subcondrales (18).

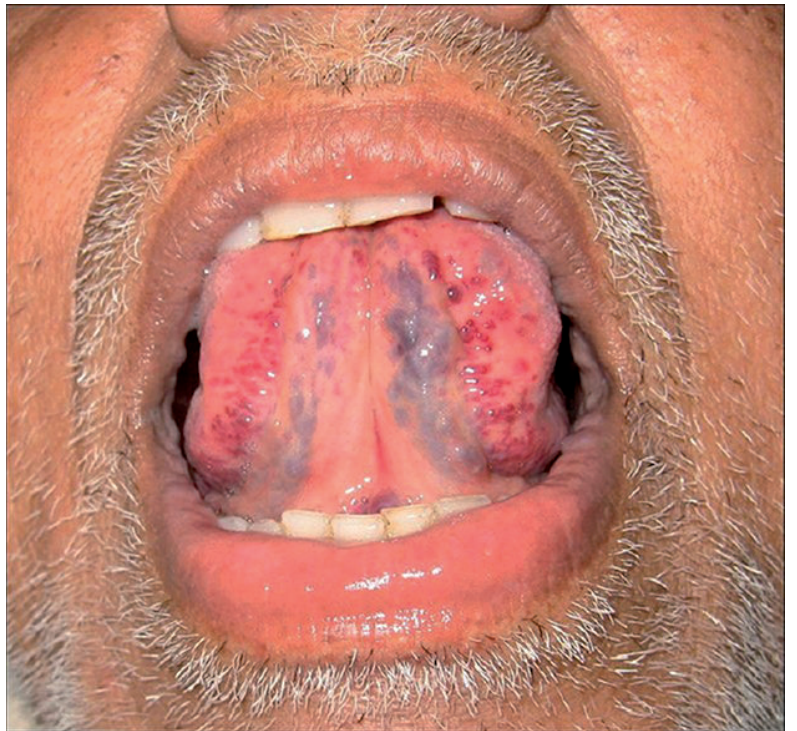

Figura 6. Varices sublinguales (23).

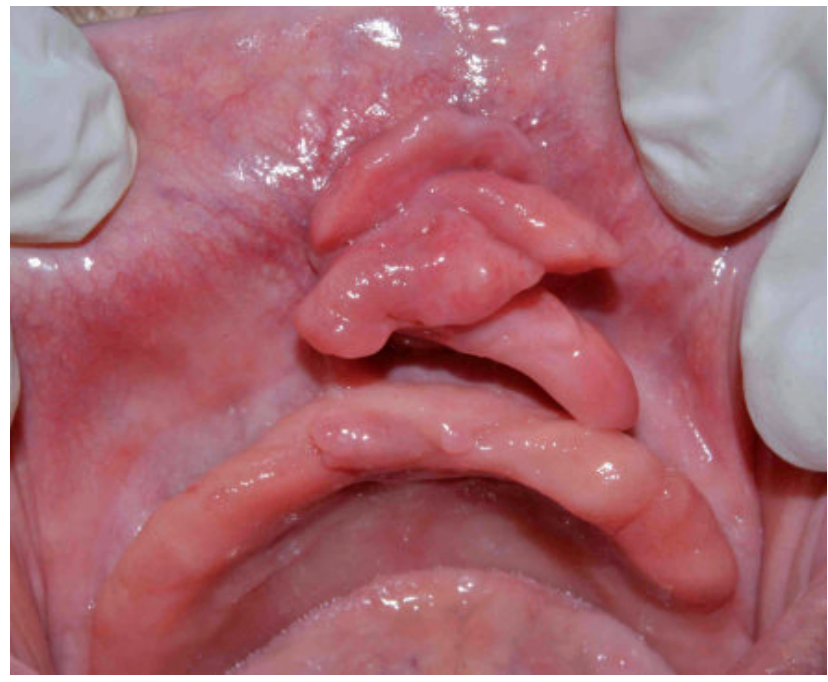

Figura 7. Estomatitis paraprotética (26).

Por otro lado, algunos pacientes pueden presentar épulis fisurado (epulis fissuratum) que es una lesión hipertrófica de la mucosa bucal, de base amplia, localizada por lo general en zonas próximas a la prótesis dental. También se puede originar irritación crónica causada por el uso continuo o permanente de prótesis desajustadas, generando así un cuadro de estomatitis paraprotética $(1,3,6,21)$ (Figura 7). Sin embargo, Rodriguez y Sacsaquispe (24) en el estudio realizado en Perú el año 2005, demostraron que esta hiperplasia fibrosa inflamatoria está relacionada a la mala higiene; y los pacientes con esta manifestación tenían compromiso sistémico, por lo 
que no necesariamente estaba relacionada al tipo de prótesis y al tiempo de uso de la misma. Así pues, esta deficiente higiene de la prótesis trae consigo el acúmulo de placa bacteriana en el interior de la misma, sobre todo en aquellas desadaptadas, permitiendo que microorganismos oportunistas como la cándida albicans estén presentes, así como también cocos y bacilos, debido a la descomposición de alimentos (25).

Es frecuente que los adultos mayores tengan lesiones producidas por infección por hongos levaduriformes (cándida) ubicados en las mucosas que recubren la boca y la lengua. Se presentan generalmente como placas blanquecinas a manera de parches que pueden ser fácilmente retiradas. Otra forma en que suele presentarse esta infección por hongos, es la cándida eritematosa, que se caracteriza por la presencia de placas de color rojo (de allí su nombre). Esta lesión puede cursar asintomática o con síntomas leves, pudiendo existir incomodidad, sensación de quemadura, ardor y sequedad en la boca $(3,6,15,16)$.

Otra característica común de las personas de la tercera edad, es la presencia de queilitis angular, lesión erosiva y blanquecina de la comisura labial producida por la pérdida de tono muscular y que puede estar asociada a infecciones como el herpes simple o deficiencia de complejo B, pudiendo ocasionar sangrado, limitación de la apertura bucal y dolor $(1,5,27)$ (Figura 8 ).

Es frecuente en los adultos mayores el trauma de oclusión secundario por el uso de prótesis

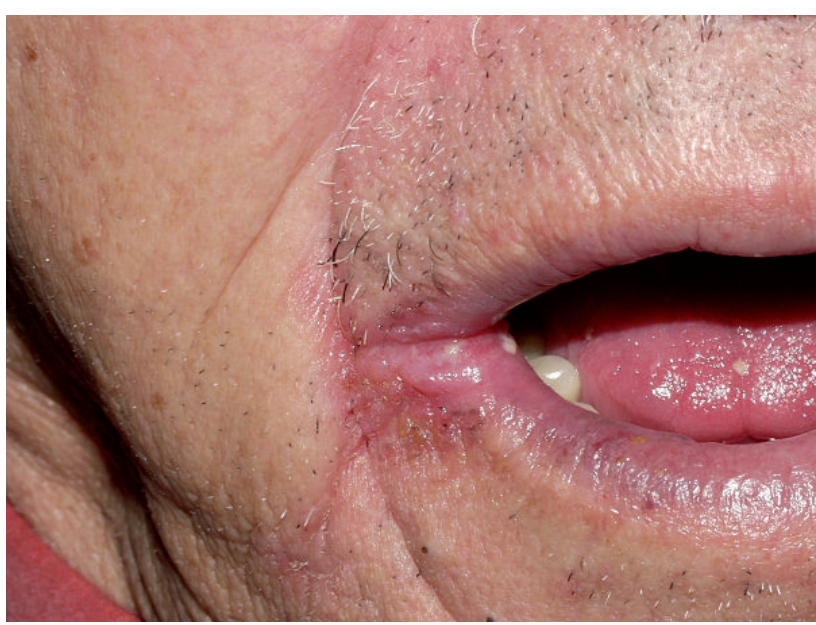

Figura 8. Queilitis angular (28). desadaptadas, dientes fracturados, restauraciones rotas, etc. Se observan también ulceras traumáticas que pueden ser lesiones únicas o múltiples caracterizadas por perdida en la continuidad de la mucosa bucal con un proceso inflamatorio subyacente con presencia súbita de sintomatología. Estas úlceras tienen diagnóstico diferencial con lesiones cancerígenas que se caracterizan por presentarse topográficamente con mayor frecuencia en la lengua, piso de la boca, labios y paladar. La etiología del cáncer bucal en la población del adulto mayor es variada y es común que coincidan diversas causas en un mismo paciente. Se asocia a una mala higiene bucal, tabaquismo, alcoholismo, deficiencias nutricionales y agentes biológicos. Por lo general, el cáncer bucal, es asintomático en los primeros estadios y puede alcanzar dimensiones considerables antes de manifestar sintomatología. Por tal motivo, en caso de encontrarse una lesión sospechosa que no desaparece en un lapso de 7 a 10 días, es conveniente referir al paciente adulto mayor al especialista para la realización de una biopsia, diagnóstico, tratamiento y seguimiento del caso $(1,3)$.

\section{CONCLUSIONES}

- Elincremento enlapoblación de latercera edad tiene implicancias sociales y demográficas importantes; por tal motivo, las sociedades actuales deben preocuparse por alcanzar entre sus metas una vejez saludable y un envejecimiento activo.

- Los problemas de salud bucal en los adultos mayores deben tomarse muy en cuenta ya que en esta etapa de la vida cobran mayor importancia, debido al impacto que tienen en su calidad de vida; así como por presentar mayor riesgo de consecuencias más severas y complejas que requieren de atención especializada.

- Es necesario que se diseñen e implementen programas preventivos eficaces dirigidos a este grupo de la población, de tal manera que se puedan prevenir los daños a la salud bucal y general, con una visión integral de la gerodontología y odontogeriatría.

- Los enfoques de atención al adulto mayor no sólo deben limitarse al tratamiento de las enfermedades y manifestaciones patológicas producto de cambios biológicos sistémicos y bucales inherentes al envejecimiento, sino también a los aspectos psicosociales que 
acompañan al proceso de envejecimiento.

- El cirujano dentista debe investigar si el paciente adulto mayor está bajo tratamiento médico y si el cuadro sistémico se encuentra estabilizado antes de realizar cualquier procedimiento; de lo contrario, es fundamental remitirlo a su médico para una valoración clínica general o especializada, aunque esto implique postergar el tratamiento odontológico.

\section{Correspondencia:}

\author{
Beatriz Del Carmen Chávez Reátegui \\ Juan Benítez No 289, Dpto. 301 - San Borja. Lima, \\ Perú. \\ Correo electrónico: beatriz.del.carmen.chavez@ \\ upch.pe
}

\section{REFERENCIAS BIBLIOGRÁFICAS}

1. Hernández R, Mendoza V, Martínez I, Morales L. Odontogeriatría y gerontología. México DF: Editorial Trillas; 2011.

2. Tin E. Odontogeriatría. Imperativo no ensinoodontologicodiante do novo perfil demográfico brasilero. Campinas SP: Editora Alinea; 2001.

3. Vandola MC, Neto A. Bases clínicas em odontogeriatria. São Paulo: Libraría Santos Editora Ltda; 2009.

4. Soria E, Perera R. Importancia de la atención odontogeriátrica en el paciente institucionalizado. Odont Act. 2013; 10(118):18-22.

5. Barrera L, Rubio R, Rubio L, Quintero M, Falque L, Zambrano R, et al. La Salud de los adultos mayores: una visión compartida. Organización Panamericana de la Salud. $2^{\mathrm{a}}$ ed. Washington D.C: Organización Panamericana de La Salud; 2011.

6. Duarte A. Consideraciones en el manejo odontológico del paciente geriátrico. Revista Científica Odontológica. 2012; 8(1):45-54.

7. Gómez J, Saiach S, Lecuna N. Envejecimiento. Revista de Posgrado de la Cátedra VIa Medicina. 2000; 100:21-3.

8. Murillo O. Envejecimiento bucodental. Anales de gerontología. 2010; (6):59-67.

9. Organización Mundial de la Salud. Envejecimiento. Ginebra: Organización Mundial de la Salud; 2010. (Citado el 24 de Agosto del 2014). Disponible en: http://www.who.int/topics/ageing/es/

10. Allevato MA, Gaviria J. Educación continua: Envejecimiento. Act Terap Dermatol. 2008; 31:154-62.

11. Sánchez S. El envejecimiento de la población y la salud bucodental. Un reto para los servicios de salud en México. Revista Odontológica Mexicana. 2009; 13(3):134-5.
12. De Alva C, Gorrogoñoitia A, Litago C, Martín I, Luque A. Actividades Preventivas en Ancianos. Aten Primaria. 2001; 28(2):161-80.

13. Vejez y vida.Aspectos básicos sobre el envejecimiento. Barcelona: Vejez y vida.; 2011. (Citado el 24 de Agosto del 2014). Disponible en: http:/www.vejezyvida.com/ aspectos-basicos-sobre-el-envejecimiento/

14. MedCiencia. La estrecha relación entre el ritmo circadiano y el envejecimiento. Catalunya: MedCiencia; 2011. (Citado el 24 de Agosto del 2014). Disponible en: http://www.medciencia.com/la-estrecha-relacionentre-el-ritmo-circadiano-y-el-envejecimiento/

15. Molina L. Algunos problemas que plantea el ejercicio de la estomatología geriátrica. Tesis Cirujano Dentista. Guatemala, Guatemala. Facultad de Odontología, Universidad Francisco Marroquín; 2003.

16. Roisinblit R. Odontología para las personas mayores. 1ra edición. Buenos Aires; 2010.

17. Programa de salud oral en grupos con mayor riesgo de vulnerabilidad social, Universidad de Murcia. Envejecimiento. Murcia: Universidad de Murcia; 2012.(Citado el 24 de Agosto del 2014). Disponible en: http://www.um.es/proyectocooperacion-guatemala/ envejecimiento/

18. Díaz S. Arrieta K, Ramos K. Impacto de la salud oral en la calidad de vida del adulto mayor. Rev Clin Fam. 2012; 5(1):9-16.

19. San Martín C, Villanueva J, Labraña G. Cambios del sistema estomatognático en el paciente adulto mayor (II parte). Revista dental de Chile. 2002; 93(3):23-6.

20. Díaz LM, Gay O. Series en medicina bucal X. Odontología de calidad para los pacientes ancianos. Revista ADM. 2005; 62(1):36-9.

21. Vargas P, Da Cruz, Jorge J, Carrinho A, Esquiche J, Paes O. Hiperplasia fibrosa asociada a prótesis con áreas simulando un papiloma oral ductual invertido. Med Oral Patol Oral Cir Bucal. 2005; 10(S2):E117-21.

22. Williams E, Montaño M. Caries en el adulto mayor, un reto para la odontología. Rev Mex Odon Clin. 2007; 1(12):10-5.

23. Viswanath V, Nair S, Chavan N, Torsekar R. Caviar tongue. Indian J Dermatol Venereol Leprol. 2011; 77(1):78-9.

24. Rodríguez AF, Sacsaquispe S. Hiperplasia fibrosa inflamatoria y posibles factores asociados en adultos mayores. Rev Estomatol Herediana. 2005; 15(2):13944.

25. García B, Benet M, Castillo E. Prótesis dentales y lesiones mucosas en el adulto mayor. Revista electrónica de las Ciencias Médicas en Cienfuegos. Medisur. 2010; 8(1):36-41.

26. Martinez B. Lesiones seudotumorales y neoplasias benignas. Santiago: Universidad Mayor de Santiago de Chile. Facultad de Odontología. Unidad de Patología Oral; 2014. (Citado el 24 de Agosto del 2014). 
Disponible en: http://patoral.umayor.cl/patoral/? $\mathrm{p}=1685$.

27. Petersen PE, Bourgeois D, Ogawa H, Estupinan-Day S, Ndiaye C. The global burden of oral diseases and risks to oral health. Bull World Health Organ. 2005; 83(9):661-9.

28. Hospital Universitari Arnau de Vilanova. Universitat de Lleida. Servei de Dermatología. ATLAS. Cataluña:
Hospital Universitari Arnau de Vilanova. Universitat de Lleida. Servei de Dermatología; 2002. (Citado el 24 deAgosto del 2014). Disponible en: http://dermatoweb2. udl.es/atlas.php?lletra=q\&idsubmenu=2600.

Recibido: 21/10/2013

Aceptado: 05/03/2014 